\title{
Research on Casing Damage Based on Effect of Water Injection Pressure
}

\author{
Liping Guo, Xu Chen, Xiaoyang Yu, Shuang Shi, Yu Wang \\ College of Petroleum Engineering, Northeast Petroleum University, Daqing, China \\ Email: glp dqsy@sina.com
}

Received 25 May 2015; accepted 21 June 2015; published 24 June 2015

Copyright (C) 2015 by authors and Scientific Research Publishing Inc.

This work is licensed under the Creative Commons Attribution International License (CC BY). http://creativecommons.org/licenses/by/4.0/

c) (i) Open Access

\begin{abstract}
Based on statistical analysis on the situation of casing damage and water injection pressure in Pubei Oilfield, it shows that the main forms of casing damage in Pubei Oilfield are deformation and dislocation. Dip angle and faults have a significant impact on casing damage and casing damage is closely related to water injection pressure. Through laboratory simulating experiment and theoretical calculation, the formula of critical injection pressure giving rise to casing damage is obtained and the preventive measures are drafted.
\end{abstract}

\section{Keywords}

\section{Casing Damage, Water Injection Pressure, Pubei Oilfield}

\section{Introduction}

With the development of the oilfield water flooding extraction, the quantity and increasing speed of oilfield casing damage are rising obviously. Casing damage not only brings about loss of economy, but also has a disadvantageous impact on oilfield development scheme and measures, which directly affects the development of oilfield. The problem of casing damage has become an urgent problem in the oilfield.

Scholars from home and abroad studied the damage of casing well [1]-[5] and they had obtained the certain understanding on the mechanism of casing damage [6]. Mechanism of casing damage is discontinuous deformation in the overlying strata and the discontinuous deformation includes interlayer sliding and fault movement induced by subsidence, which results in casing shear damage; axial compression and bending of casing are caused by large vertical displacement and pore pressure goes down; reservoir becomes compaction. Axial load transfers to the cement ring from strata, then to the casing and casing damage is destroyed due to yield or bending. The casing extrusion damage in the middle of production floor is because of the largest axial strain and casing bent because of excessive axial load and its surroundings without sufficient lateral support [7]. Channeling is easily 
caused when water injection pressure surpasses fracture pressure in the case of poor cementing quality. In the case of water channel, immersion area forms and strata stress is out of balance, which results in that the casing damage area forms in large immersion area [8]. However, there is no effective way to prevent and slow the damage of casing well. In Pubei Oilfield as an example, distribution law of casing damage is raised and the effect rule and mechanism that water injection pressure acts on casing damage of injection wells and oil wells are studied.

\section{General Situation and Distribution of Casing Damage in Pubei Oilfield}

\subsection{General Situation of Casing Damage}

By the end of 2010, the number of casing-damaged wells in the seventh oil production plant of Daqing Oilfield is 355, among which 247 are injection wells, and 108 are oil wells. Casing-damaged injection wells accounts for $80.28 \%$ of the total casing-damaged wells. There are 285 casing-damaged wells in Pubei Oilfield, which accounts for $80.28 \%$ of the total number of the seventh oil production plant of Daqing Oilfield. The main forms of casing damage are deformation and dislocation. 168 wells emerge casing dislocation and deformations appear in 153 wells. Casing-damaged wells with these two kinds of forms account for $90.42 \%$ of the total casing-damaged wells. In vertical casing damage mainly emerge in reservoirs.

The second and third blocks are the main casing damage blocks in Pubei Oilfield, and the number of casingdamaged wells is 163 , which accounts for $64.68 \%$ of total casing-damaged wells in Pubei Oilfield. Casingdamaged wells account for $19.52 \%$ of the oil and water wells in the second block; while in the third block the percentage is $16.23 \%$.

\subsection{Distribution of Casing Damage}

Analyze the distribution statistical data of casing-damaged wells along north and south direction in the second block with regression method to obtain the curve and mathematical relation of casing damage rate (see Figure 1).

$$
N=152.846-11.337 S_{n}+0.2268 S_{n}^{2}-0.0012 S_{n}^{3}
$$

Figure 1 shows that the rate of casing damage increases gradually from north to south and reaches a maximum in the 79th row wells, after which the rate of casing damage decreases gradually.

Analyze the distribution statistical data of casing-damaged wells along north and south direction in the third block with regression method to obtain the curve and mathematical relation of casing damage rate (see Figure 2).

$$
N=-44.634+0.832 S_{n}
$$

Figure 2 shows that the rate of casing damage increases linearly from north to south, which indicates that casing damage in south is much more serious than in North. The most serious casing damage is in the 94th row wells and the rate of casing damage is $40 \%$.

From the comparison between Figure 1 and Figure 2, it shows that casing damage in the second block is much more serious than in the third block. Casing damage of oil water wells is directly related to water injection of oilfield. The higher water injection pressure is, the greater the chance of casing damage is; the more injection wells and the higher formation pressure difference between injection wells and oil water wells can cause casing damage easily.

\section{Relationship between Water Injection Pressure and Casing Damage of Injection Well}

\subsection{Distribution of Casing Damage}

The oil pressure distribution of the second block in 2007 and the third block in 2010 are taken as examples, and the relationship between oil pressure and well array of water injection wells is analyzed. The results are shown in Figure 3 and Figure 4.

Figure 3 shows that the oil pressure of water injection wells in the second block increases gradually from north to south and reaches a maximum in the 79th row well, which is basically consistent with the curve of 


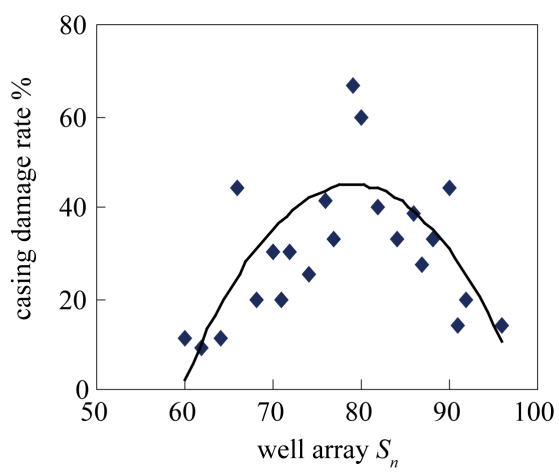

Figure 1. Casing damage rate along north-south direction in the second block.

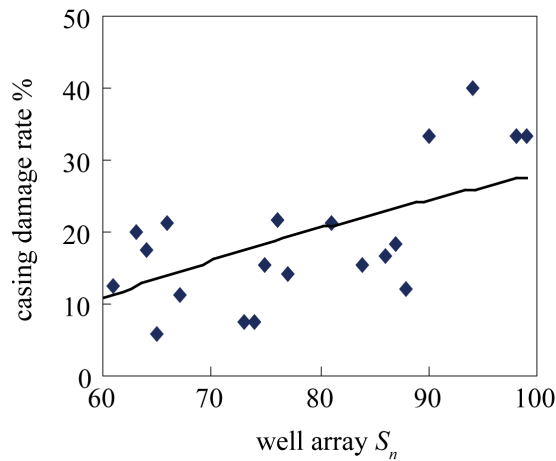

Figure 2. Casing damage rate along north-south direction in the third block.

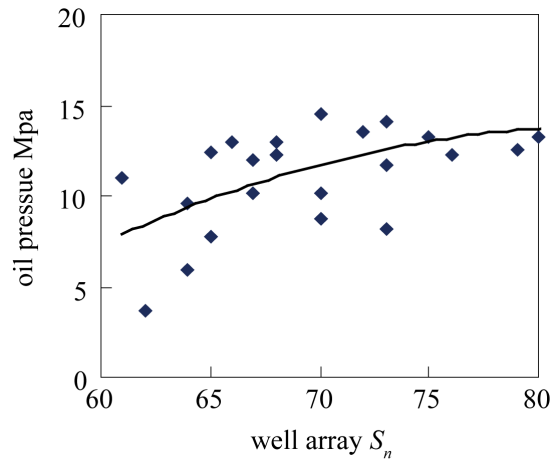

Figure 3. Oil pressure distribution of the second block in 2007.

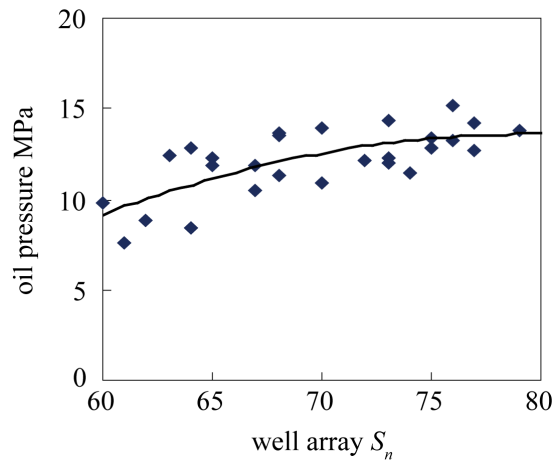

Figure 4. Oil pressure distribution of the third block in 2010. 
casing damaging rate.

Figure 4 shows that the oil pressure of water injection wells in the third block increases lineally from north to south, which is basically consistent with the curve of casing damaging rate, too.

\subsection{Laboratory Experiment of Casing Damage}

Two goals are intended to achieve through this experiment. The first is to examine the horizontal stress caused by rock creep deformation crush casing when the overburden pressure is very large; the second is to simulate the shear damage of casing when the formation deforms and slips [9].

The result of the first test shows that even load around casing can make the diameter of casing shrink but make no shear damage on casing. This shows that symmetric external force will not cause shear damage on casing.

The result of the second test shows that the damage form is bearing a two-way stress (shear force and axial force) which can decrease the intensity of casing. The damage processes of casing are bending first and then having shear deformation and partial hole shrinkage. The casing deformation includes elastic deformation and plastic deformation; plastic deformation accounts for $32 \%$ of the total deformation. If the diameter of casing is $139.7 \mathrm{~mm}$, the plastic deformation can be $44.7 \mathrm{~mm}$. This shows that the relative sliding between formations can cause antisymmetrical external force, which can lead to shear damage on casing.

The casing-damaged wells in Pubei Oilfield are distributed dispersedly not in large area, so the casing damage is caused by formation slipping of local individual wells, not vast formation displacement. There are two necessary conditions for formation slipping. The first is internal condition: weak structure surface exists in formation and the structure surface is argillization. The second is external condition: high pressure water injection in water injection oilfield. When injection pressure reaches to a certain value, a retting area forms, which first leads to emollescence even argillization of mudstone. It reduces the rock cohesion greatly and then reduces internal friction angle of rock.

The principle to judge the instability of rock mass is Mohr-Coulomb criterion [10]-[12]. As shown in Figure 5 , the angle between weak surface and the outside normal direction of maximum major stress is $\beta$, therefore, the normal stress and shear stress on this surface is:

$$
\begin{gathered}
\tau_{n}=\frac{\sigma_{1}-\sigma_{3}}{2} \sin 2 \beta=\left(\sigma_{1}-\sigma_{3}\right) \sin \beta \cos \beta \\
\sigma_{n}=\frac{\sigma_{1}+\sigma_{3}}{2}+\frac{\sigma_{1}-\sigma_{3}}{2} \cos 2 \beta .
\end{gathered}
$$

The limit equilibrium condition of rock mass is:

$$
\tau_{n}=\tau_{0}+\sigma_{n} \tan \phi
$$

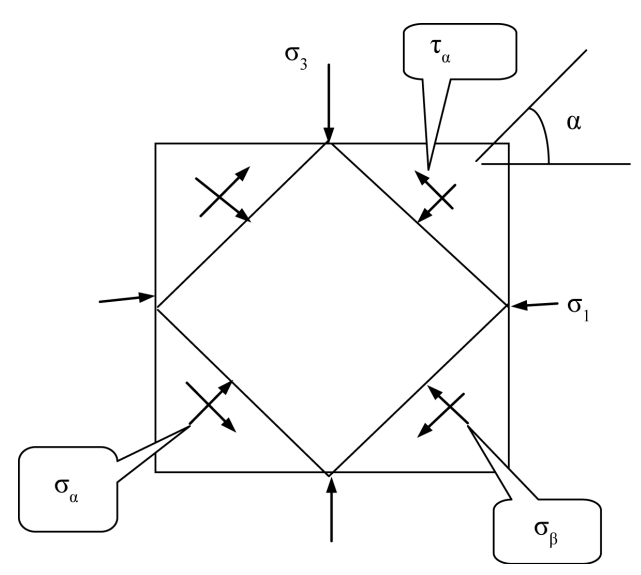

Figure 5. Relationship between major stress and normal stress. 
Take (3) and (4) into (5):

$$
\left(\sigma_{1}-\sigma_{3}\right) \sin \beta \cdot \cos \beta=\tan \phi\left(\sigma_{1} \cos ^{2} \beta+\sigma_{3} \sin ^{2} \beta\right)+\tau_{0} .
$$

When the pore water pressure of mud shale formation is $p_{0}$, the effective stresses of $\sigma_{1}$ and $\sigma_{3}$ are

$$
\begin{aligned}
& \sigma_{1}^{\prime}=\sigma_{v}-p_{0} \\
& \sigma_{3}^{\prime}=\sigma_{h}-p_{0} .
\end{aligned}
$$

Take $\sigma_{1}$ and $\sigma_{3}$ into equilibrium condition (5):

$$
p_{0}=\frac{\sigma_{V} \cos \beta(\cos \beta \tan \phi-\sin \beta)+\sigma_{h} \sin \beta(\cos \beta+\sin \beta \tan \phi)+\tau_{0}}{\tan \phi} .
$$

\subsection{The Calculation of Original Crustal Stress in Pubei Oilfield}

The vertical crustal stress $\sigma_{v}$ is caused by the gravity of overlying formation, the overburden pressure at depths of $H$ meters is [13]-[15]:

$$
\sigma_{v}=\int_{0}^{H} \rho(h) \cdot g \cdot \mathrm{d} h=\int_{0}^{H} 2.06 \mathrm{e}^{8.8 \times 10^{-5} h} \mathrm{~d} h=\left.\frac{2.06}{8.8 \times 10^{-5}} \mathrm{e}^{8.8 \times 10^{-5 h}}\right|_{0} ^{H} .
$$

Based on the data of formation breakdown of Pubei Oilfield and the relationship between bursting pressure and crustal stress, the calculating model of horizontal crustal stress is:

$$
\begin{gathered}
\sigma_{H}=\left(\frac{\mu_{s}}{1-\mu_{s}}+1.563\right)\left(\sigma_{v}-P_{p}\right)+P_{p} \\
\sigma_{h}=\left(\frac{\mu_{s}}{1-\mu_{s}}+0.523\right)\left(\sigma_{v}-P_{p}\right)+P_{p} .
\end{gathered}
$$

\subsection{Rock Mechanics Parameters Experiment}

Triaxial compression tests were done on 16 cores from Pu68-Jian862 wells (Yao Yi) in Pubei Oilfield. Four rock samples are selected to take the hydrated triaxial compressive strength test. The internal friction angle, cohesive strength, Poisson ratio, Young's modulus of sandstone, mudstone and hydrated mudstone are obtained, and then Mohr strength envelope equation of Pubei Oilfield is obtained [16].

Sandstone:

$$
\tau=15.7+\sigma \tan (33.28)
$$

Mudstone:

$$
\tau=23.73+\sigma \tan (36)
$$

Hydrated mudstone:

$$
\tau=20.9+\sigma \tan (12.55)
$$

\subsection{Calculation of Water Injection Pressure to Prevent the Casing from Damage in Pubei Oilfield}

According to the theories mentioned above, the water injection pressure is:

$$
\begin{aligned}
\sigma_{V} & =\frac{2.064238}{8.8 \times 10^{-5}}\left(\mathrm{e}^{8.8 \times 10^{-5} H}-1\right) \\
\sigma_{h} & =0.742 \sigma_{V}-0.00258 * H .
\end{aligned}
$$

The calculating formula of critical formation pressure is [17] [18]: 


$$
\begin{cases}p_{0}=2275.34 \mathrm{e}^{8.8 \times 10^{-5} H}+2.987 \times 10^{-4} H-2273.63, & \left(\theta \geq 3^{\circ}\right) \\ p_{0}=2375.00 \mathrm{e}^{8.8 \times 10^{-5} H}+1.962 \times 10^{-4} H-2373.29, & \left(\theta=1^{\circ}-3^{\circ}\right) \\ p_{0}=2473.86 \mathrm{e}^{8.8 \times 10^{-5} H}+0.974 \times 10^{-4} H-2472.15, & \left(\theta \leq 1^{\circ}\right)\end{cases}
$$

Through the calculation, it shows that among 112 casing-damage injection wells, the number of ones whose water injection pressure is more than strata critical pressure is 86 , accounting for $76.8 \%$ of the number of casing-damage wells. So water injection with more than critical pressure of formation is the main cause of casing damage.

For 76 - 78 wells, the depth of oil reservoir top is $978.3 \mathrm{~m}, \sigma_{v}=21.08 \mathrm{MPa}, \sigma_{h}=18.2 \mathrm{MPa}$, and the strata dip of this block is $3^{\circ}$, the critical formation pressure for calculation is $22.25 \mathrm{MPa} . \sigma_{1}=21.27 \mathrm{Mpa}, \sigma_{3}=7.09 \mathrm{Mpa}, \varphi$ $=25, C=1.5 \mathrm{Mpa}$. The well casing damage occurred in March 2008. Before this the water injection pressure is 23.15 MPa and the time of water injection with more than critical pressure of formation is 13 months, causing the casing damage of wells.

\section{Relationship between Water Injection Pressure and Casing Damage in Oil Well}

Great diastrophism will be caused when water injection pressure is too high, resulting casing damage of oil wells around water injection wells. Through the field data, it shows that when mudstone layer is not hydrous, relative slipping layer is in the mudstone layer above water injection layer, but not in water injection layer. The slipping occurs in the side of fault. The maximum affected scope of slippage is $150 \mathrm{~m}$, and the maximum interlayer slippage is in the mudstone layer above water injection layer, $130 \mathrm{~m}$ from water injection well; When the formation pressure reaches $27 \mathrm{MPa}$, the number of maximum inter slippage is $3.0 \mathrm{~cm}$. Relative vertical slipping emerges in fault surface below water injection layer. When the formation is not hydrated and the formation pressure is less than $16 \mathrm{MPa}$, there is no interlayer slipping. When the formation pressure is more than $16 \mathrm{MPa}$, tiny deformation emerges and number of the maximum slippage increases lineally as the increase of formation pressure.

When Mudstone layer is hydrous, relative slipping layer is in the mudstone layer above water injection layer. The slipping occurs in the side of fault; The maximal affected scope of slippage is $330 \mathrm{~m}$, and the maximum interlayer slippage is in the mudstone layer above water injection layer, $210 \mathrm{~m}$ from water injection well; When the formation pressure reaches $27 \mathrm{MPa}$, the number of the maximum inter slippage is $4.5 \mathrm{~cm}$. When the formation is not hydrated and the formation pressure is less than $14 \mathrm{MPa}$, there is no interlayer slipping. When the formation pressure is more than $14 \mathrm{MPa}$, tiny deformation emerges and number of the maximum slippage increases lineally as the increase of formation pressure.

Among 51 casing-damage oil wells of the second and third blocks in Pubei Oilfield, there are 34 casing-damage wells on one side of the fault, accounting for $68.6 \%$ of the number of casing-damage wells; there are 45 casing-damage wells in the upper mudstone layer, accounting for $89.4 \%$ of the number of casing-damage wells; The number of casing-damage oil wells that formation pressure of adjacent water injection is between 14 and 16 MPa is 3, so shale hydration has happened in such wells.

\section{Conclusions}

1) The main reason of casing damage in Pubei Oilfield is the interlayer slipping between lays with different lithologic characters. Water injection pressure is the driving force that leads to interlayer slipping. The hydration of mudstone layer above water injection formation is the significant reason that induces interlayer slipping. As the increase of water injection pressure, the interlayer slippage increases, and after a certain water injection pressure, slippage increases linearly. Slipping layer is not in water injection layer but in the mudstone layer above water injection layer. The maximum slippage is between injection wells and fault. After the mudstone layer is hydrated, as the increase of water injection pressure, the affected scope of slippage can be more than 300 $\mathrm{m}$ and the maximum slippage can be $4 \mathrm{~cm}$.

2) Prevention measures of casing damage: to control the retting and hydration of mudstone layer to prevent casing damage and to decrease water injection near fault as far as possible to prevent retting and slipping of fault are suggested. For area where the water injection pressure is higher, the water injection pressure is suggested to 
be reduced to be below critical pressure. In the formation that is not hydrated, the formation pressure should be less than $24 \mathrm{MPa}$; in the hydrous formation, the formation pressure should be less than $22 \mathrm{MPa}$.

\section{Fund Project}

National Natural Science Foundation of China (No. 51404072).

\section{References}

[1] Clinedinst, W.O. (1994) 5C3-1994 Bulletin on Formulas and Calculations for Casing, Tubing, Drill Pipe and Line Pipe Properties Apibulletin. American Petroleum Institute, Washington.

[2] Khnalaf, F. (1985) Increasing Casing Collapse Resistance against Salt-Induced Loads. Society of Petroleum Engineers, 12, 259-265.

[3] Asbill, W.T., Livesay, R. and Crabtree, S. (2002) Modernization of Tubular Collapse Performance Proerties. API/HSE/ MMs Participant Report.

[4] Sutton, D.L. and Sabins, F.L. (1990) Interrelationship between Critical Cement Properties and Volume Changes during Cement Settings. SPE20451.

[5] Ai, C., Wang, C. and Guo, Z. (2003) Statistical Analysis of Factors of Casing Failure in Pubei Oilfield. Journal of Daqing Petroleum Institute, 27, 23-24.

[6] Ai, C. (2003) Mechanism and Theoretic Models of Casing Failure and Numerical Calculation with Them. Ph.D. Thesis, Northeast Petroleum University, Daqing.

[7] Wang, C. (2005) Mechanic Analyse and Calculate of Casing Failure in Jilin Oilfield. M. Thesis, Northeast Petroleum University, Daqing.

[8] Gao, J.G. (2013) Research on Casing Damage Caused by Injecting Water and Finite Element Emulation. M. Thesis, Northeast Petroleum University, Daqing.

[9] Liu, J.Z. (1993) Oilfield Stress Measuring. Seismological Press, Beijing, 1-20.

[10] Diao, S., Yang, C.H., Liu, J.J. and Huang, X.L. (2008) Mechanism of Seepage Induced Casing Damage and Numerical Simulation. Rock and Soil Mechanics, 2, 24-29.

[11] Wang, L.J., Lv, B., Wu, F., Shao, Z.J. and Yang, M. (2006) Method for Formation Fracture Pressure Prediction of Water Injection Wells and Its Application. Journal of Daqing Petroleum Institute, 4, 6-10.

[12] Zhou, Y.J., Jia, J.H. and Li, R.H. (2010) Casing Damage Forecasting Method and Its Application in the Process of Oilfield Development. Journal of China University of Petroleum, 6, 32-25.

[13] Jia, J.H. (2001) Casing Damage Forecasting Method and Its Application in the Process of Oilfield Development. China University of Petroleum, 25-55.

[14] Ai, C. (2003) Mechanism and Theoretic Models of Casing Failure and Numerical Calculation with Them. Daqing Petroleum Institute, 1-25.

[15] Liu, H. (2003) Mechanism and Control of Casing Damage in Oil Wells. Petroleum Industry Press, 5-39.

[16] Cai, G.H. and Wang, X.R. (2001) Prevention of Casing Damage Caused by High Pressure Waterflooding. China Petroleum Machinery, 3, 32-34.

[17] Xie, G.M., Zhang, L.W. and Zhang, Z.L. (2001) Analysis of the Casing Damage Causes in the Evaporite Bed of Jianghan Oilfield. Oil Drilling \& Production Technology, 4, 30-33.

[18] Tian, J., Liu, X.G. and Shang, G.H. (2005) Casing Damage Mechanism Based on Theory of Fluid-Solid Coupling Flow through Underground Rock. Journal of Hydrodynamics, 2, 45-49. 